\section{Radiofrequency ablation of gastric antral vascular ectasia of the gastric cardia}

A 63-year-old woman was referred for iron-deficiency anemia and melena that was requiring multiple blood transfusions. She had undergone multiple uninformative upper endoscopies and colonoscopies that had been performed by two different gastroenterologists. The patient had undergone a capsule endoscopy that had shown a questionable vascular ectasia in the distal ileum. She therefore underwent retrograde single-balloon enteroscopy; this showed melena from the terminal ileum to the middle jejunum. Given this finding, indicating a more proximal gastrointestinal bleed, an upper endoscopy was performed that showed a prominent erythematous ring of vascular ectasias in the gastric cardia just below the gastroesophageal junction; this was consistent with gastric antral vascular ectasia (GAVE) of the gastric cardia ( $\bullet$ Fig. 1, $\bullet$ Video 1 ). Given the circular distribution of the ectasias, the lesion appeared ideal for ablation with a focal radiofrequency ablation (RFA) catheter $($ Fig. 2, $\bullet$ Video 1 ). The patient underwent three sessions of RFA, each 2 months apart. By the fourth endoscopy, 6 months after the first endoscopy, the GAVE had resolved ( $\bullet$ Fig. 3, $\bullet$ Video 1 ). Despite its name, GAVE can occur in other areas of the gastrointestinal tract besides the antrum of the stomach. GAVE can occur in the gastric cardia of the stomach, and in the duodenum, jejunum, and rectum $[1,2]$. GAVE can be seen in the gastric cardia as an erythematous ring, extending just below the gastroesophageal junction [1]. As the present case demonstrates, it is important to recognize this, as GAVE in the cardia can easily be missed.

Historically, GAVE has been treated endoscopically with argon plasma coagulation or by band ligation [2,3]. However, more recently RFA has been shown to be effective and safe in treating GAVE, especially in cases refractory to argon plasma coagulation $[4,5]$. Given the circular distribution of the GAVE in the gastric cardia in this patient, the RFA focal ablation device was chosen to ablate the GAVE in a $360^{\circ}$ fashion.

\section{Endoscopy_UCTN_Code_TTT_1AO_2AD}

Competing interests: The authors declare that no conflicts of interest or financial relationships exist.

\section{Arvind J. Trindade, Sumant Inamdar, David Magier}

Division of Gastroenterology, Hofstra Northwell School of Medicine, Northwell Health System, Long Island Jewish Medical Center, New Hyde Park, New York, USA

\section{References}

1 Parikh K, Ali MA, Wong RCK. Unusual causes of upper gastrointestinal bleeding. Gastrointest Endosc Clin N Am 2015; 25: 583-605

2 Fuccio L, Mussetto A, Laterza L et al. Diagnosis and management of gastric antral vascular ectasia. World J Gastrointest Endosc 2013; 5: 6-13

3 Zepeda-Gómez S, Sultanian R, Teshima C et al. Gastric antral vascular ectasia: a prospective study of treatment with endoscopic band ligation. Endoscopy 2015; 47: 538 - 540

4 Gross SA, Al-Haddad M, Gill KRS et al. Endoscopic mucosal ablation for the treatment of gastric antral vascular ectasia with the HALO90 system: a pilot study. Gastrointest Endosc 2008; 67: 324-327

5 Dray X, Repici A, Gonzalez P et al. Radiofrequency ablation for the treatment of gastric antral vascular ectasia. Endoscopy 2014; 46: 963-969

\section{Bibliography}

DOI http://dx.doi.org/

10.1055/s-0042-116819

Endoscopy 2016; 48: E301

(c) Georg Thieme Verlag KG

Stuttgart · New York

ISSN 0013-726X

\section{Arvind J. Trindade, MD}

Long Island Jewish Medical Center, Hofstra Northwell School of Medicine, Northwell Health System 270-05 76th Avenue

New Hyde Park, NY 11040 USA

Fax: +1-718-470-5509

arvind.trindade@gmail.com

\section{Corresponding author}

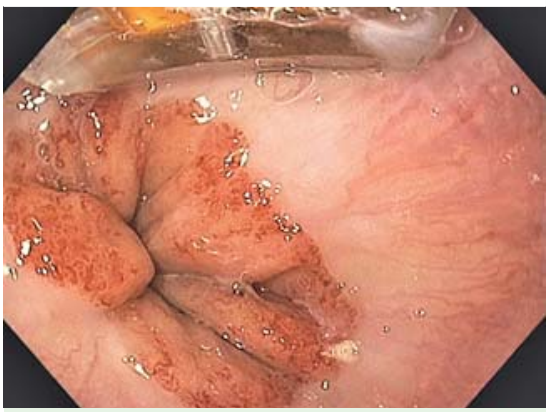

Fig. 1 In a 63-year-old woman, referred for iron-deficiency anemia and melena requiring multiple blood transfusions, an upper endoscopy showed an erythematous ring of vascular ectasias in the gastric cardia just below the gastroesophageal junction, that was consistent with gastric antral vascular ectasia (GAVE).

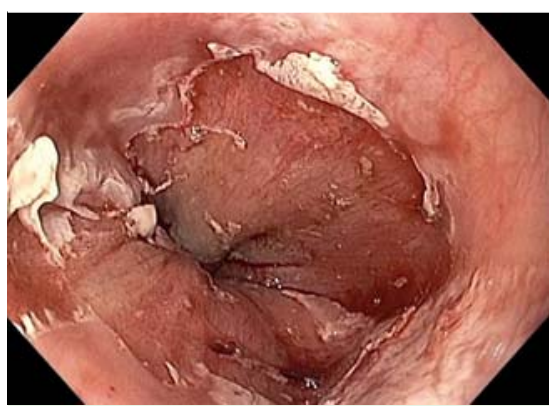

Fig. 2 Gastric antral vascular ectasia (GAVE) of the gastric cardia after the first session of radiofrequency ablation (RFA).

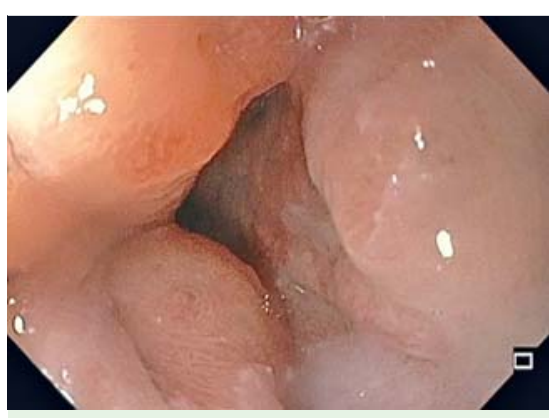

Fig. 3 The gastric cardia after three sessions of RFA: the GAVE has resolved.

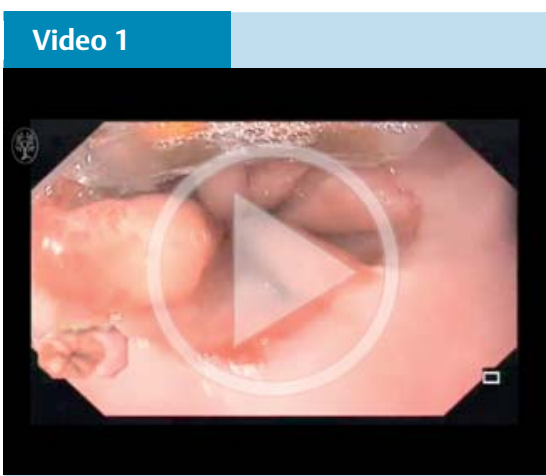

Gastric antral vascular ectasia (GAVE) of the gastric cardia treated using a focal radiofrequency ablation (RFA) device, and subsequent resolution of the GAVE. 